\title{
Multiple paternity in the cooperatively breeding fish Neolamprologus pulcher
}

\author{
P. Dierkes $\cdot$ M. Taborsky $・$ R. Achmann
}

Received: 10 June 2007 /Revised: 25 March 2008 /Accepted: 4 April 2008 /Published online: 28 May 2008

(C) Springer-Verlag 2008

\begin{abstract}
In cooperative breeders, mature males may compete for fertilizations. In this study, we measured the degree of multiple paternity in a natural population of a cooperatively breeding fish. Neolamprologus pulcher (Perciformes: Cichlidae) is a highly social cichlid endemic to Lake Tanganyika. We used highly variable microsatellite loci to survey 12 groups with an average number of 10.6 brood care helpers per group and a total of 43 offspring (mean 3.6 per brood). In 11 of 12 groups, all young were assigned to the dominant female. The dominant male sired all offspring in three groups, part of the offspring in four groups, and in five groups, he had no paternity at all. In total, $44.2 \%$ of young were not fathered by the current male territory owner. Multiple paternity was found in 5 of 12 broods $(41.7 \%)$, with 8 of 35 young $(22.9 \%)$ being sired by males other than the respective territory owners. This is an exceptionally high rate of extra-pair paternity among cooperatively breeding vertebrates. Neither helpers present
\end{abstract}

Communicated by K. Lindström

P. Dierkes $\cdot$ M. Taborsky

Konrad Lorenz Institut für Vergleichende Verhaltensforschung,

Savoyenstr. 1A,

A-1160 Vienna, Austria

P. Dierkes $\cdot$ M. Taborsky $(\bowtie)$

Department of Behavioural Ecology, Institute of Zoology,

University of Berne,

CH-3032 Hinterkappelen/Bern, Switzerland

e-mail: michael.taborsky@esh.unibe.ch

R. Achmann

Ludwig-Boltzmann-Institute for Cyto-, Immuno- and Molecular

Genetic Research, University of Veterinary Medicine,

Veterinärplatz 1,

A-1210 Vienna, Austria in these territories during collection nor neighbouring males were unequivocally assigned to have sired these extra-pair young. However, behavioural observations suggest that male helpers may have produced these young before being expelled from the territory in response to this reproductive parasitism. We discuss these results in the light of reproductive skew theory, cooperative breeding in vertebrates and alternative reproductive tactics in fish.

Keywords Parentage $\cdot$ Microsatellites $\cdot$ Cichlids . Lake Tanganyika $\cdot$ Alternative mating tactics

\section{Introduction}

In cooperatively breeding species, helpers in brood care and territory maintenance may bear considerable costs from their activities (Reyer 1984; Taborsky 1984; Heinsohn and Cockburn 1994; Clutton-Brock et al. 1998; Grantner and Taborsky 1998; Taborsky and Grantner 1998). A variety of benefits may compensate for these costs. Helpers may benefit by obtaining brood care experience (Lawton and Guindon 1981; Komdeur 1996) or pay for being allowed to stay in the territory (Taborsky 1984, 1985; Mulder and Langmore 1993; Balshine-Earn et al. 1998; Bergmüller and Taborsky 2005; Begmüller et al. 2005a) to gain protection in the group territory (Gaston 1978a; Taborsky 1984; Heg et al. 2004) or to benefit later by inheriting a territory or mate (Gaston 1978b; Woolfenden and Fitzpatrick 1978; Balshine-Earn et al. 1998). Often, helpers increase their inclusive fitness by helping to raise relatives (Hamilton 1964; Taborsky and Limberger 1981; Reyer 1984; Taborsky 1984; Clutton-Brock et al. 2001; Russell and Hatchwell 2001; Brouwer et al. 2005). Genetic parentage analyses revealed that they may also benefit by sharing in reproduc- 
tion (Rabenold et al. 1990; Lundy et al. 1998; Dierkes et al. 1999; Richardson et al. 2001). This latter observation illustrates the potential reproductive conflict among cooperating members in advanced social systems (Taborsky 1985, 1994; Keller and Reeve 1994; Johnstone and Cant 1999; Johnstone 2000; West et al. 2002; Clutton-Brock et al. 2006; Komdeur 2006).

In the cichlid fish Neolamprologus pulcher, breeders tolerate sexually mature individuals of both sexes in their territory, which causes reproductive conflict (Taborsky and Limberger 1981; Taborsky 1984, 1985; Dierkes et al. 1999). Optimal reproductive skew theory predicts that the reproductive share between group members should depend primarily on the relatedness between breeders and helpers, the cost/benefit ratios to helpers and breeders if the subordinates stay or leave and the relative abilities to control reproduction within the group (Emlen 1982; Vehrencamp 1983a, b; Keller and Reeve 1994; Johnstone 2000). A number of studies have dealt with these predicted determinants of reproductive skew in N. pulcher (Taborsky and Limberger 1981; Taborsky 1984; 1985; Skubic et al. 2004; Stiver et al. 2004; Dierkes et al. 2005; Heg et al. 2006). In this cooperatively breeding cichlid, helpers run the risk of being expelled from their territory by the dominant breeders. For male helpers, this may be a direct response of breeders to an attempted participation in reproduction (Taborsky 1985; Dierkes et al. 1999). The aim of this study was to quantify the relative proportions of parentage within groups in a natural population of $N$. pulcher at Lake Tanganyika. Multiple paternity is very frequent in fish with paternal care, mainly due to simultaneous parasitic spawning (SPS; Taborsky 1994, 1997, 2001, 2008; Avise et al. 2002). SPS occurs when males that do not invest in the monopolisation of mating access surreptitiously shed sperm onto eggs during spawning events of bourgeois males (Taborsky 1994). It was described to occur also within groups of $N$. pulcher in a standardised laboratory experiment (Dierkes et al. 1999).

\section{Materials and methods}

\section{Study species}

$N$. pulcher is widely distributed along the rocky shores of Lake Tanganyika, Africa at depths ranging from 3 to $45 \mathrm{~m}$. Originally, $N$. pulcher and $N$. brichardi have been described as two species with type specimen originating from different populations of the north and south of Lake Tanganyika. Recent morphological and genetic scrutiny has not confirmed species status of these populations, however (Grantner and Taborsky 1998; Duftner et al. 2007). Breeding groups of this species consist of a breeder male and female and 1-17 helpers of both sexes (Taborsky and Limberger 1981; Balshine-Earn et al. 2001). Breeder males may monopolise more than one breeding group, resulting in harems of two to four groups that defend separate territories, each consisting of a female breeder and helpers but sharing the same male breeder (Limberger 1983; Dierkes et al. 2005). Helpers are usually offspring produced in the territory where they are found, but some exchange between territories can occur (Taborsky and Limberger 1981; Stiver et al. 2004; Bergmüller et al. 2005b; Dierkes et al. 2005). Due to frequent exchange of breeders, in the southern population studied here, the large, sexually mature helpers are usually not closely related to the owners of their territory (and the latters' offspring; Dierkes et al. 2005). Immature and mature helpers of both sexes assist breeders by cleaning and fanning eggs and larvae, defending the territory against space competitors and predators and by removing sand and particles from the shelters (Taborsky and Limberger 1981; Taborsky 1984; Stiver et al. 2005). Sexually mature group members leave the territory frequently for plankton feeding in the water column, but they return regularly to the territory for hiding, and to share in reproductive and maintenance duties and in territory defence.

\section{Sampling and genetic analyses}

At our study site at Kasakalawe Point (4 km west of Mpulungu, Zambia; approximately $8^{\circ} 47^{\prime} \mathrm{S}, 31^{\circ} 05^{\prime} \mathrm{E}$ ), we collected 12 whole groups containing fry, from two colonies in 9-m (11 groups) and 11-m depth (one group, labelled no. 2), respectively. These groups included 191 individuals in total: 20 breeders (12 female breeders, five monogamous males and three harem males monopolising two, three and four groups, respectively; only two groups of the four-group harem contained fry, so of this harem, only these two groups were included in this study), 128 helpers and 43 fry (i.e. young, free-swimming offspring).

Before catching these fish, their territories were marked, and group composition was checked thoroughly at least twice on subsequent days. We attempted to catch the entire group at a time with a conical tent net, which we put over the territory when both breeders and all subordinate group members were present according to our knowledge of group composition from the previous observations. From each individual standard length (SL, body length in centimeter measured to the nearest millimeter from front end of body to base of tail fin) and body weight were measured. We sexed all fish of 3.5-cm SL (i.e. approximate size when reaching sexual maturity; Taborsky 1985) and larger by examining their genital papillae. The day after catching, we checked neighbouring groups for potential changes in composition that might have resulted from catching. 
The fish were preserved in dimethyl sulfoxide buffer (Seutin et al. 1991) for transport and storage. For DNA extraction, a tissue part (mainly muscle) from above the lateral line from each adult, or the complete tail from small helpers, or a whole fry was used. The extraction followed a protocol of Sambrook et al. 1989.

Five microsatellite DNA loci were analysed to determine paternity and maternity. Primer sequences for locus 773 , locus 780 and locus 007 have been derived from the Central-African cichlid Tilapia deckeri (Schliewen et al. 2001). Primer sequences for locus UME003 (GenBank accession number: U 14397) were developed for Pseudotropheus zebra, a Lake Malawi cichlid (Parker and Kornfield 1996). Primers for locus 101 were developed for Lamprologus ocellatus, a shell brooding cichlid from Lake Tanganyika (Brandtmann et al. 1999). Forward primers were labelled with fluorescent dyes, 773a, 101a and 007a with 6-FAM (blue), 780a with TET (green), UME003a with HEX (yellow).

Forty nanograms of genomic DNA was used in a $15 \mu \mathrm{l}$ polymerase chain reaction (PCR) containing $1.5 \mu \mathrm{l} 10 \times$ PCR buffer, $2.5 \mathrm{mM} \mathrm{MgCl}, 0.5 \mu \mathrm{M}$ of each primer, $0.2 \mathrm{mM}$ dNTPs and $0.75 \mathrm{U} \mathrm{Taq}$ polymerase (Agrobiogen, Germany). PCR (1: multiplexing group, 773, 007, 780, and 003 ; 2: group 101 with repetitions, if necessary) was performed in a Perkin Elmer cycler set (Geneamp 3600) for $10 \mathrm{~min}$ of initial denaturation at $94^{\circ} \mathrm{C}$ followed by 30 cycles of denaturation at $94^{\circ} \mathrm{C}$ for $30 \mathrm{~s}$, annealing at $56^{\circ} \mathrm{C}$ for $40 \mathrm{~s}$ and extension at $72^{\circ} \mathrm{C}$ for $70 \mathrm{~s}$ followed by a final 1 -h extension at $72^{\circ} \mathrm{C}$. Four microlitres of the PCR product were mixed with $40 \mu \mathrm{l}$ formamid solution, followed by a 5-min denaturation at $98^{\circ} \mathrm{C}$ and placed directly on ice before loading on to an automatic capillary sequencer (ABI Prism 310 Genetic Analyser, Perkin Elmer). GENESCANTM500, TAMRA (red) was used as a length standard by mixing $5 \mu \mathrm{l}$ with $150 \mu \mathrm{l}$ formamid. The standard was put on the capillary first for gauging. ABI's GENESCAN software gave base size information of each capillary run, followed by a fragment analysis with ABI's GENOTYPER software.

Basic population genetic statistics were generated with the computer program CERVUS 2.0 (Marshall et al. 1998). Possible deviations of the genotype frequencies per locus from expectations based on Hardy-Weinberg equilibrium were analysed with GENEPOP (Raymond and Rousset 1995, version $3.4 \mathrm{http}: / /$ wbiomed.curtin.edu/genepop/). For this purpose and for generating a population allele frequency, we used a larger data set, 334 samples in total, containing fish collected concurrently in the same population (see Table 1).

Parentage analysis

Parentage assignment and exclusion was performed with help of CERVUS 2.0 software on the basis of the number of
Table 1 Marker polymorphism in N. pulcher

\begin{tabular}{lccccc}
\hline Locus & $\begin{array}{c}\text { No. of } \\
\text { alleles }\end{array}$ & $H_{\mathrm{E}}$ & $H_{\mathrm{O}}$ & $\begin{array}{c}\text { Exclusion power } \\
\text { of first parent }\end{array}$ & $\begin{array}{l}\text { Exclusion power } \\
\text { of second parent }\end{array}$ \\
\hline 773 & 14 & 0.48 & 0.50 & 0.14 & 0.32 \\
007 & 13 & 0.55 & 0.53 & 0.17 & 0.34 \\
780 & 36 & 0.93 & 0.90 & 0.74 & 0.85 \\
UME003 & 34 & 0.93 & 0.91 & 0.75 & 0.86 \\
101 & 24 & 0.84 & 0.86 & 0.51 & 0.68 \\
\hline
\end{tabular}

The numbers of alleles, expected $\left(H_{\mathrm{E}}\right)$ and observed $\left(H_{\mathrm{O}}\right)$ heterozygosities are shown. Exclusion power estimates combined over five loci, given for first and second assigned parent.

mismatching alleles. Candidate parents assessed were all group members (breeders and sexually mature helpers). From the CERVUS 2.0 analyses, we determined the number of mismatching alleles for all female-male combinations in each group. First, we attempted to assign maternity to the group female (female breeder) within the group. Second, once a female was assigned, we attempted to assign paternity to the male breeder (territory owner) and if it was excluded to all helper males of that particular group. Third, if none of the group member males could be assigned, we tried to find the father among the breeding males and mature male helpers from neighbouring territories. Finally, when offspring could not be assigned to any genotyped potential father, we used GERUD 2 (Jones 2005) to estimate the minimum number of males that participated in siring the offspring of a brood and to reconstruct their genotypes. We scored the data carefully by manual comparison and investigated if at the focal locus, the same alleles were expressed in other offspring within the same brood not sired by the dominant male.

With GERUD 2, we also checked for consistency of paternity within size cohorts of helpers within groups (i.e. presumed to belong to the same brood). Manual comparison was necessary in broods with less than three offspring and only possible in families where the genotyped mother of a cohort was still present in the group and genotyped. We regarded helpers as resulting from parasitic paternity when alleles did not match with those of other fish from the same cohort in the same group (i.e. they were only half-sibs of the other cohort members).

To test for Mendelian inheritance, we bred a group in the lab. Parentage analysis showed an inheritance in a Mendelian fashion.

\section{Results}

The 12 analysed groups had $10.6 \pm 5.1$ helpers per group (mean \pm SD; range 4-20), i.e. 128 helpers between 1.3- and $5.2-\mathrm{cm} \mathrm{SL}$ were contained in the total sample. There were 
3.6 free-swimming fry per group (=mean; range $1-8$ ) with sizes of $0.6-$ to $1.1-\mathrm{cm}$ SL (i.e. approximately 10-40 days of age; Fig. 1). In total, the groups had 23 helpers of at least $3.5-\mathrm{cm}$ SL (i.e. potentially sexually mature, 14 males and nine females). Two of the 12 groups with fry had no sexually mature helpers at all (see Fig. 1).

Parentage assignment

All five microsatellite loci were highly variable, with 13 to 36 alleles per locus (mean $=24.2$; Table 1), and average heterozygosity was $75 \%$ (for both expected and observed). Total exclusion power was 0.978 for the first parent and
0.997 for the second parent for all five loci combined. One locus, 101, deviated from Hardy-Weinberg equilibrium $(p<0.04)$; such occasional deviations are expected to occur in group-living animals with non-random mixing of genotypes and reproductive skew. It is still possible to include this locus into parentage tests with the CERVUS analysis.

In 11 of 12 groups, all fry were assigned to the dominant female, and only in group no. 2 was the dominant female excluded to be the mother (Table 2). Parentage was assigned when no mismatching loci were found, and parentage exclusion was assumed when one to five mismatching loci occurred.
Fig. 1 Sizes and sex-specific composition of the studied groups. Black bars mark the male territory owner (the largest individual was always the male breeder) and the offspring fathered by these males. EPY are marked with fasciated bars. Cross-hatched bars mark female breeders, hatched bars potentially mature female helpers, grey bars potentially mature male helpers and blank bars juvenile helpers. The dashed line at $3.5-\mathrm{cm}$ standard length denotes the size above which individuals are potentially sexually mature
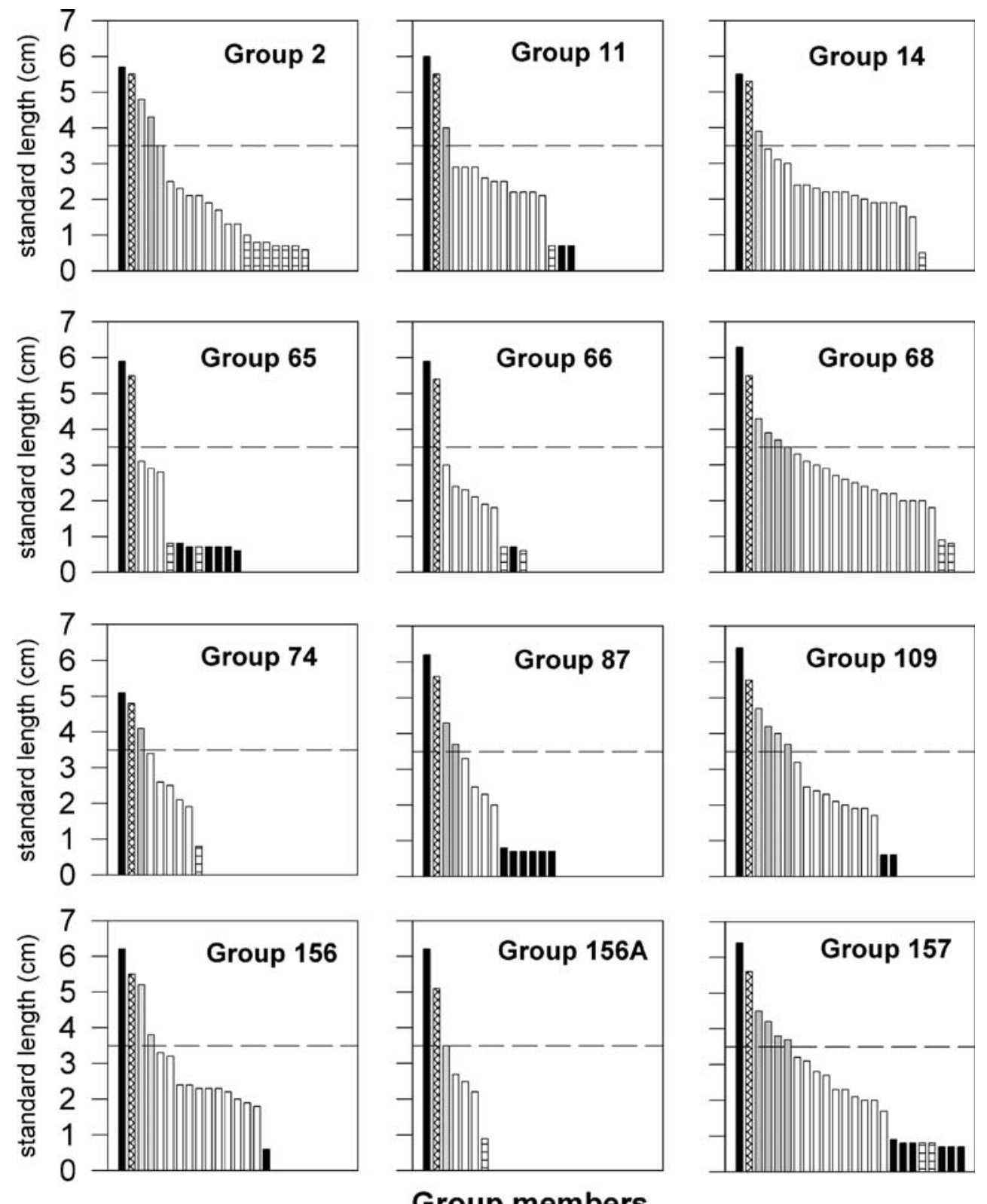
Table 2 Paternity and maternity by territory owners in 12 groups of $N$. pulcher collected in the field with small offspring (microsatellite data from five loci)

\begin{tabular}{|c|c|c|c|c|c|c|}
\hline Group ID & Brood size & $\begin{array}{l}\text { Loci to exclude } \\
\text { territory male }\end{array}$ & $\begin{array}{l}\text { Loci to exclude } \\
\text { territory female }\end{array}$ & $\begin{array}{l}\text { Minimum } \\
\text { no. of fathers }\end{array}$ & $\begin{array}{l}\text { Mature male } \\
\text { helpers }\end{array}$ & $\begin{array}{l}\text { Mature female } \\
\text { helpers }\end{array}$ \\
\hline $2^{b}$ & 7 & 4333344 & 22222222 & 2 & 1 & 1 \\
\hline 11 & 3 & 200 & 000 & 2 & 1 & 0 \\
\hline 14 & 1 & 2 & 0 & 1 & 0 & 0 \\
\hline 65 & 8 & 20050000 & 00000000 & 2 & 0 & 0 \\
\hline 66 & 3 & 103 & 000 & 2 & 0 & 0 \\
\hline 68 & 2 & 33 & 00 & 1 & 3 & 1 \\
\hline 74 & 1 & 5 & 0 & 1 & 1 & 0 \\
\hline 87 & 6 & 000000 & 000000 & 1 & 2 & 0 \\
\hline 109 & 2 & 00 & 00 & 1 & 2 & 2 \\
\hline 156 & 1 & 0 & 0 & 1 & 0 & 1 \\
\hline $156 \mathrm{~A}$ & 1 & 3 & 0 & 1 & 0 & 0 \\
\hline 157 & 8 & 00120000 & 00000000 & 2 & 4 & 1 \\
\hline
\end{tabular}

Bold numbers mark the EPY in broods and give numbers of loci at which the male/female breeders were excluded.

${ }^{\text {a }}$ In group no. 2, the male breeder sired no young, but in addition, this brood showed evidence of multiple paternity.

${ }^{\mathrm{b}}$ Minimum number of fathers in broods with three or more offspring was estimated with help of a GERUD 2.0 analysis; in broods with less than three offspring it was determined by manual comparison.

\section{Paternity}

In 3 of the 12 sampled groups, all fry were assigned to the dominant male, in four groups, the dominant male was excluded to be the father of part of the offspring, and in five groups, the present male territory holders were excluded to have sired any of the fry (Table 2). In total, 19 of the 43 fry $(44.2 \%)$ were not sired by the dominant male. In the five groups where no fry at all could be assigned to the dominant male (12 fry in total), the male breeder may have been replaced between spawning and fry collection. Therefore, these fry cannot be safely assigned to parasitic spawnings. Of the four broods with mixed paternity, 7 of 22 fry $(31.8 \%)$ were not sired by the dominant male; in two of these groups, no sexually mature male helpers were present (groups no. 65 and no. 66), and in the other two groups (no. 11 and no. 157), the present mature male helpers $(N=5)$ were excluded from paternity.

In group no. 2, neither the female nor male breeder sired any of the seven offspring. Most likely, a replacement of the pair of breeders had occurred between spawning and collection of the fry. One of the seven young of this brood had an allele which none of its siblings shared. The large male helper of this group shared all alleles of this particular young. We assume that this fry was only a half-sibling to the other young. In group no. 157, two of the nine fry were not fathered by the breeding male, and the CERVUS analysis suggested a helper male as the most likely father of one of the two extra-pair-young (EPY). But this particular helper could be excluded with one non-matching allele from paternity of this offspring and with two non-matching alleles from paternity of the other offspring. In both broods (groups no. 2 and no. 157), GERUD analyses suggested two fathers of the fry, respectively (see Table 2).

For group no. 11, all males belonging to three of four directly neighbouring territories were sampled, and there was no male to which paternity of the extra-pair fry in group 11 could be assigned ( $N=5$ mature males). For the harem no. 65/no. 66, two of four directly neighbouring groups were sampled. None of the four mature males living in these groups sired the four extra-pair fry in harem no. 65/ no. 66. No male group members were sampled from territories neighbouring the groups no. 2 and no. 157 .

We checked for multiple paternity also among size cohorts of helpers within groups with three or more young per cohort (i.e. young of previous broods). In group no. 14, one helper of 13 of its cohort, in group no. 68, two helpers of 12 and in group no. 157, two helpers of nine had incompatible (third) alleles and therefore were only halfsiblings of the other helpers in the same cohort. For these cohorts, the GERUD analysis suggested two fathers each. Hence, it is most likely that these helpers have resulted from multiple paternity.

Multiple paternity occurred in the two-female's harem, in the four-female's harem and in two non-harem groups. The paternity levels of harem males did not differ significantly from those of monogamous males, with harem males siring $64.3 \%$ and monogamous males $80.0 \%$ of the fry they were caring for $(p=0.79, N=3$ harem groups, 5 non-harem groups, Mann-Whitney $U$-Test, $U=6.0$ ). 


\section{Discussion}

Our parentage analysis revealed that multiple paternity of broods is frequent in $N$. pulcher. In 11 of 12 groups (92\%), the dominant female was assigned to be the mother of all fry. Only in one case (group no. 2) were both male and female territory owners excluded to be the parents of the young, which suggests that a pair replacement had occurred in this group between spawning and our collection of fry. In this group, one of seven fry was not a full sibling of the other six, and a large male helper shared all alleles with this young, which indicates potential paternity of this helper. However, as we do not know the mother of this offspring, we cannot safely conclude that it was fathered by this particular helper, although it appears likely. In group no. 157, the CERVUS analysis suggested a helper with one mismatching locus as the most likely father, which might be taken as hint on helper parasitism by a brother of this helper that was no longer present.

In total, three exclusions were based on one mismatching locus only. As mismatching loci may also originate from mistyping or point mutations, we checked these three cases very carefully. In all three cases, the deviating allele was not shown by members of the same brood, but by larger helpers in the respective groups. In no case was the deviating allele a neighbour allele from a known allele, i.e. similar in base pair numbers. Hence, we exclude a typing error for these results. GERUD analyses suggested two fathers for each of the particular broods. However, we cannot rule out completely that mutations may have caused the occurrence of these deviating alleles, although this is a rare event (microsatellite mutation rate estimates range from $10^{-5}$ to $10^{-2}$; Ellegren 2000) and can certainly not explain all three cases. Nevertheless, when excluding all three offspring that deviate only by one allele from the results to arrive at the most conservative figure, 5 of 32 (15.6\%; instead of $22.9 \%$, see below) offspring would have not been sired by the dominant male territory owner in broods with multiple paternity, which is probably an underestimate.

Brood mixing can be excluded as a mechanism causing multiple parentage in $N$. pulcher fry in the field because they stay close to the breeding shelter, distances between territories are too large, and predation is very high (Taborsky and Limberger 1981; Stiver et al. 2004). Therefore, there are two possible reasons for the observed pattern of extra-pair paternity: (1) reproductive parasitism by helpers or non-group members, as was the case probably in the five broods with mixed paternity (including group no. 2) and (2) male breeder replacement after the brood had been produced. In 5 of the 12 groups $(41.7 \%)$, the male territory owner was not the father of any of the fry. As in four of these groups the respective broods contained only one or two fry each, we cannot safely decide between these possibilities. To obtain a more conservative estimate of the proportion of EPY produced in $N$. pulcher groups, we confine this analysis to broods with three or more young. The proportion of EPY in the six broods to which this criterion applies was $22.9 \%$ ( 8 of 35 fry). If we had included all 12 broods in this analysis irrespective of their size, this proportion would be $30.2 \%$ EPY (13 of 43 fry), which is probably an overestimate. We expected that paternity levels of harem males might be lower than those of monogamous males due to their greater distraction potential during spawning, but these levels did not differ significantly from each other. We should like to stress, however, that this analysis suffered from low statistical power because of small sample sizes.

What is the origin of EPY in N. pulcher groups? In four groups, multiple paternity was detected. In only two of these were sexually mature male helpers present at the time of sampling (one and four individuals, respectively), and paternity was excluded for all five of these helpers. We should not conclude from these results, however, that the extra-pair young produced in these groups had not been sired by male helpers. Mature helpers are expelled by breeders on the day of spawning with a very high probability (16 times more likely than between broods; Taborsky 1985), which is probably mainly due to the helpers' potential participation in reproduction. Male helpers may have performed SPS and were then expelled from the territory, as was observed to occur repeatedly in a laboratory experiment (Dierkes et al. 1999; but see Heg et al. 2006). A dynamic state variable model predicts that attempts to parasitize the breeders' reproduction should be highly constrained by punishment through expulsion (Skubic et al. 2004). Despite the fact that none of the EPY could be unequivocally assigned to a male helper, we regard it as likely that multiple paternity was at least partly caused by SPS of helpers. Males that were not members of the colony can be ruled out as parasitic spawners because between-colony dispersal is very low (Heg et al. 2004; Stiver et al. 2004). When one or two mature helpers were present in the territory in a controlled lab experiment, $10.3 \%$ of the offspring produced were sired by these helpers (Dierkes et al. 1999). In our field study reported here, on average, there was a similar number of mature male helpers in the groups at the time of collection (eight male helpers $>3.5 \mathrm{~cm}$ in six groups with sufficient numbers of fry) as in the laboratory experiments (eight male helpers $>3.5 \mathrm{~cm}$ in seven groups). Still, the number of EPY was more than twice as high in the field than in the lab situation. There are several possibilities to explain this difference. (1) The fertilization efficiency of helpers may be greater in the field situation, e.g. because in nature, it is more difficult for breeders to keep mature male helpers at bay. (2) The number of helpers may have been greater at spawning than 
when the groups were collected; this is likely because of the observation that helpers are often expelled on the day of spawning and in response to reproductive parasitism (Taborsky 1985; Dierkes et al. 1999). (3) EPY may have been sired also by male intruders, although we found no evidence for EPY paternity of neighbouring males. Successful parasitic spawning of helpers from neighbouring groups was found to occur occasionally in a laboratory study (Heg et al. 2006), and regular visits by helpers of neighbouring groups have been observed in the field outside of spawning events (Bergmüller et al. 2005b).

In contrast to the frequent occurrence of intragroup reproductive competition in cooperatively breeding fish (Pelvicachromis pulcher: Martin and Taborsky 1997; N. pulcher: Taborsky 1985; Dierkes et al. 1999; Heg et al. 2006; N. multifasciatus, Kohler 1998; Julidochromis ornatus: Awata et al. 2005), multiple paternity in cooperatively breeding birds is more often caused by extra-group fertilisations than by shared paternity within the group. In noisy miners (Manorina melanocephala), for example, all extra-pair young were fathered by individuals from other groups (Poldmaa et al. 1995), while in superb fairy wrens (Malurus cyaneus), even $76 \%$ of young were sired by extragroup males, and only $2.2 \%$ of young were sired by helpers (Mulder et al. 1994; see also Brooker et al. 1990). At the other extreme, in stripe-backed wrens (Campylorhynchus nuchalis) $8.7 \%$ of young were sired by helpers, and only in one case $(1.4 \%)$ was extra-group parentage likely (Rabenold et al. 1990). A balance between within-group and amonggroup extra-pair parentage was found in bicoloured wrens (Campylorhynchus griseus), although generally, the level of extra-pair paternity was low in this species $(4.6 \%$; Haydock et al. 1996). In most cooperatively breeding birds studied so far, however, no or almost no extra-pair parentage was found (e.g. red-cockaded woodpeckers, Picoides borealis, Haig et al. 1994; bell miners, Manorina melanophrys, Conrad et al., 1998; white-fronted bee-eaters, Merops bullockoides, Wrege and Emlen 1987; bushtits, Psaltriparus minimus, Bruce et al. 1996; laughing kookaburras, Dacelo novaeguineae, Legge and Cockburn 2000). This suggests that in cooperative breeders, within-group competition for reproduction may be less important in birds than in fish (Taborsky 1985; Martin and Taborsky 1997; Kohler 1998; Dierkes et al. 1999, this study) and perhaps also in mammals (Rood 1990; O'Riain et al. 2000; Clutton-Brock et al. 2006; Young et al. 2006). One reason for this difference may be the fact that relatedness levels are usually much higher in the family groups of cooperatively breeding birds and mammals than in cooperatively breeding fish, which may limit the payoffs of intragroup extra-pair fertilisations in the former taxa due to the risk of inbreeding.

There have been many attempts to explain the variation of intragroup parentage in highly developed social systems with the help of optimal skew theory (Vehrencamp 1983a, b; Clutton-Brock 1998; Reeve et al. 1998; Johnstone 2000). Optimal skew models assume either that breeders may benefit from conceding part of the offspring production to subdominants so that the latter stay in the group and continue to help (Keller and Reeve 1994) or that the breeders' ability to control the subdominants' reproduction is limited (Cant 1998). Among cooperatively breeding fish, there is one example in which reproductive concession appears to be responsible for the reproductive share of subordinate male helpers. In Pelvicachromis pulcher, helpers share reproduction with their harem owners when the harem has three or more females. Females spawn with these helper males even when the harem owner is in the territory. The reproductive success of dominant helpers was as high as that of pair males (Martin and Taborsky 1997). In contrast, in two other cooperatively breeding cichlids, there is evidence that male breeders cannot fully control egg fertilisation by male helpers. In Julidochromis ornatus, male helpers that were mostly unrelated to dominant breeders sired as many young as the male breeders did (44\% of young sired by helpers; Awata et al. 2005). In N. pulcher, behavioural observations and genetic data also suggest that breeders have incomplete control over their helpers' participation in reproduction (Taborsky 1985; Dierkes et al 1999; Heg et al. 2006). In this species, helpers appear to pay for being allowed to stay in the territory by their helping behaviour (Taborsky 1984, 1985; Balshine-Earn et al. 1998; Bergmüller and Taborsky 2005; Bergmüller et al. 2005a), and tug-of-war models seem most adequate to describe the reproductive sharing of group members (Heg et al. 2006; see also Skubic et al. 2004 for an alternative approach).

In fish, multiple paternity and SPS are generally very frequent (Taborsky 1994, 1998, 2001, 2008). The relative reproductive success of parasitic males has been measured in several studies (see Avise et al. 2002 for review). In most of the species known for male reproductive parasitism, competition between males of different types leads to conflict and exploitation of bourgeois male investment by reproductive parasites (Taborsky 1997, 1999). Only in very few species is cooperation between reproductive competitors known (reviewed in Taborsky 1994, 2008). Just like in most fish species known to have non-cooperative alternative reproductive tactics, male tactics are not fixed for life in N. pulcher (Taborsky 2001). If they survive, helpers become dominant breeders at a later stage of their lives. Reproductive parasitism of helpers in $N$. pulcher may sometimes lead to a situation that is unique in fish breeding systems: Parasitic spawners may care for their own young.

Acknowledgements We would like to thank Matthias Müller and Gottfried Brem for providing lab facilities. Andrea Kunz assisted in 
the field. Dolores Schütz, Gudrun Pachler and Sigal Balshine-Earn contributed by numerous discussions. Special thanks to Eva Skubic and Dik Heg for discussion, help and constructive comments on the manuscript. The work was funded by the Austrian Science Fund (FWF: project P10916-BIO) and the Swiss National Science Foundation (SNSF: project 3100A0-105626). This study complies with the current laws of Zambia, Austria and Switzerland.

\section{References}

Avise JC, Jones AG, Walker D, DeWoody JA, Dakin B, Fiumera A, Fletcher D, Mackiewicz M, Pearse D, Porter B, Wilkins SD (2002) Genetic mating systems and reproductive natural histories of fishes: lessons for ecology and evolution. Annu Rev Genet $36: 19-45$

Awata S, Munehara H, Kohda M (2005) Social system and reproduction of helpers in a cooperatively breeding fish (Julidochromis ornatus) in Lake Tanganyika: field observations and parentage analyses. Behav Ecol Sociobiol 58:506-516

Balshine-Earn S, Neat FC, Reid H, Taborsky M (1998) Paying to stay or paying to breed? Field evidence for direct benefits of helping behavior in a cooperatively breeding fish. Behav Ecol 9:432-438

Balshine-Earn S, Leach B, Neat F, Reid H, Taborsky M, Werner N (2001) Correlates of group size in a cooperatively breeding cichlid fish. Behav Ecol and Sociobiol 50:134-140

Bergmüller R, Taborsky M (2005) Experimental manipulation of helping in a cooperative breeder: helpers 'pay to stay' by preemptive appeasement. Anim Behav 69:19-28

Bergmuller R, Heg D, Taborsky M (2005a) Helpers in a cooperatively breeding cichlid stay and pay or disperse and breed, depending on ecological constraints. Proc R Soc B 272:325-331

Bergmuller R, Heg D, Peer K, Taborsky M (2005b) Extended safe havens and between-group dispersal of helpers in a cooperatively breeding cichlid. Behaviour 142:1643-1667

Brandtmann G, Scandura M, Trillmich F (1999) The female-female conflict in the harem of a snail cichlid (Lamprologus ocellatus): behavioural interactions and fitness consequences. Behaviour 136:1123-1144

Brooker MG, Rowley I, Adams M, Baversock PR (1990) Promiscuity: an inbreeding avoidance mechanism in a socially monogamous species? Behav Ecol Sociobiol 26:191-199

Brouwer L, Heg D, Taborsky M (2005) Experimental evidence for helper effects in a cooperatively breeding cichlid. Behav Ecol 16:667-673

Bruce JP, Quinn JS, Sloane SA, White BN (1996) DNA fingerprinting reveals monogamy in the bushtit, a cooperatively breeding species. Auk 113:511-516

Cant MA (1998) A model for the evolution of reproductive skew without reproductive suppression. Anim Behav 55:163-169

Clutton-Brock TH (1998) Reproductive skew, concessions and limited control. Trends Ecol Evol 13:288-292

Clutton-Brock TH, Gaynor D, Kansky R, MacColl ADC, McIlrath G, Chadwick P, Brotherton PNM, O'Riain JM, Manser M, Skinner JD (1998) Costs of cooperative behaviour in suricates (Suricata suricatta). Proc R Soc B 265:185-190

Clutton-Brock TH, Russell AF, Sharpe LL, Brotherton PNM, McIlrath GM, White S, Cameron EZ (2001) Effects of helpers on juvenile development and survival in meerkats. Science 293:2446-2449

Clutton-Brock TH, Hodge SJ, Spong G, Russell AF, Jordan NR, Bennett NC, Sharpe LL, Manser MB (2006) Intrasexual competition and sexual selection in cooperative mammals. Nature 444:1065-1068

Conrad KF, Clarke MF, Robertson RJ, Boag PT (1998) Paternity and the relatedness of helpers in the cooperatively breeding bell miner. Condor 100:343-349

Dierkes P, Taborsky M, Kohler U (1999) Reproductive parasitism of broodcare helpers in a cooperatively breeding fish. Behav Ecol 10:510-515

Dierkes P, Heg D, Taborsky M, Skubic E, Achmann R (2005) Genetic relatedness in groups is sex-specific and declines with age of helpers in a cooperatively breeding cichlid. Ecology Letters 8:968-975

Duftner N, Sefc KM, Koblmüller S, Salzburger W, Taborsky M, Sturmbauer C (2007) Parallel evolution of facial stripe patterns in the Neolamprologus brichardi/pulcher species complex endemic to Lake Tanganyika. Mol Phylogen Evol 45:706-715

Ellegren H (2000) Heterogeneous mutation processes in microsatellite DNA sequences. Nat Genet 24:400-402

Emlen ST (1982) The evolution of helping. I. An ecological constraints model. Am Nat 119:29-39

Gaston AJ (1978a) Demography of the jungle babbler, Turdoides striatus. J Anim Ecol 47:845-870

Gaston AJ (1978b) The evolution of group territorial behavior and cooperative breeding. Am Nat 112:1091-1100

Grantner A, Taborsky M (1998) The metabolic rates associated with resting, and with the performance of agonistic, submissive and digging behaviours in the cichlid fish Neolamprologus pulcher (Pisces: Cichlidae). J Comp Physiol B 168:427-433

Haig SM, Walters JR, Plissner JH (1994) Genetic evidence for monogamy in the cooperatively breeding red-cockaded woodpecker. Behav Ecol Sociobiol 34:295-303

Hamilton WD (1964) The genetical evolution of social behaviour I and II. J Theor Biol 7:1-52

Haydock J, Parker G, Rabenold KN (1996) Extra pair paternity uncommon in the cooperatively breeding bicolored wren. Behav Ecol Sociobiol 38:1-16

Heg D, Bachar Z, Brouwer L, Taborsky M (2004) Predation risk is an ecological constraint for helper dispersal in a cooperatively breeding cichlid. Proc R Soc B 271:2367-2374

Heg D, Bergmuller R, Bonfils D, Otti O, Bachar Z, Burri R, Heckel G, Taborsky M (2006) Cichlids do not adjust reproductive skew to the availability of independent breeding options. Behav Ecol 17:419-429

Heinsohn R, Cockburn A (1994) Helping is costly to young birds in cooperatively breeding white-winged choughs. Proc R Soc Lond B 256:293-298

Jones AG (2005) GERUD 2.0: a computer program for the reconstruction of parental genotypes from half-sib progeny arrays with known or unknown parents. Mol Ecol Notes 5:708-711

Johnstone RA (2000) Models of reproductive skew: A review and synthesis. Ethology 106:5-26

Johnstone RA, Cant MA (1999) Reproductive skew and the threat of eviction: a new perspective. Proc R Soc B 266:275-279

Keller L, Reeve HK (1994) Partitioning of reproduction in animal societies. Trends Ecol Evol 9:98-103

Kohler U (1998) Zur Struktur und Evolution des Sozialsystems von Neolamprologus multifasciatus (Cichlidae, Pisces), dem kleinsten Schneckenbuntbarsch des Tanganjikasees. PhD thesis, LudwigMaximilians Universität München, Germany

Komdeur J (1996) Influence of helping and breeding experience on reproductive performance in the Seychelles warbler: a translocation experiment. Behav Ecol 7:326-333

Komdeur J (2006) Variation in individual investment strategies among social animals. Ethology 112:729-747 
Lawton MF, Guindon CF (1981) Flock composition, breeding success, and learning in the brown jay. Condor 83:27-33

Legge S, Cockburn A (2000) Social and mating system of cooperatively breeding laughing kookaburra (Dacelo novaeguineae). Behav Ecol Sociobiol 47:220-229

Limberger D (1983) Pairs and harems in a cichlid fish, Lamprologus brichardi. Z Tierpsychol 62:115-144

Lundy KJ, Parker PG, Zahavi A (1998) Reproduction by subordinates in cooperatively breeding Arabian babblers is uncommon but predictable. Behav Ecol Sociobiol 43:173-180

Marshall TC, Slate J, Kruuk LEB, Pemberton JM (1998) Statistical confidence for likelihood-based paternity inference in natural populations. Mol Ecol 7:639-655

Martin E, Taborsky M (1997) Alternative male mating tactics in a cichlid, Pelvicachromis pulcher: a comparison of reproductive effort and success. Behav Ecol Sociobiol 41:311-319

Mulder RA, Dunn PO, Cockburn A, Lazenby-Cohen KA, Howell MJ (1994) Helpers liberate female fairy wrens from constraints on extra-pair mate choice. Proc R Soc Lond B 255:223-229

Mulder RA, Langmore N (1993) Dominant males punish helpers for temporary defection in superb fairy-wrens. Anim Behav 45:830 833

O'Riain MJ, Bennett NC, Brotherton PNM, McIlrath G, CluttonBrock TH (2000) Reproductive suppression and inbreeding avoidance in wild populations of co- operatively breeding meerkats (Suricata suricatta). Behav Ecol Sociobiol 48:471-477

Parker A, Kornfield I (1996) Polygynandry in Pseudotropheus zebra, a cichlid fish from Lake Malawi. Environ Biol Fishes 47:345-352

Poldmaa T, Montgomerie R, Boag P (1995) Mating system of the cooperatively breeding noisy miner Manorina melanocephala, as revealed by DNA profiling. Behav Ecol Sociobiol 337:137-143

Rabenold PP, Rabenold KN, Piper WH, Haydock J, Zack SW (1990) Shared paternity revealed by genetic analysis in cooperatively breeding tropical wrens. Nature 348:538-540

Raymond M, Rousset F (1995) GENEPOP (version 1.2): population genetics software for exact tests and ecumenicism. J Heredity $86: 248-249$

Reeve HK, Emlen ST, Keller L (1998) Reproductive sharing in animal societies: reproductive incentives or incomplete control by dominant breeders? Behav Ecol 9:267-278

Reyer HU (1984) Investment and relatedness: a cost/benefit analysis of breeding and helping in the pied kingfisher (Ceryle rudis). Anim Behav 32:1163-1178

Richardson DS, Jury FL, Blakmeer K, Komdeur J, Burke T (2001) Parentage assignment and extra-group paternity in a cooperative breeder: the Seychelles warbler (Acrocephalus sechellensis). Mol Ecol 10:2263-2273

Rood JP (1990) Group size, survival, reproduction and routes to breeding in dwarf mongooses. Anim Behav 39:566-572

Russell AF, Hatchwell BJ (2001) Experimental evidence for kinbiased helping in a cooperatively breeding vertebrate. Proc R Soc B 268:2169-2174

Sambrook J, Fritsch EF, Maniatis T (1989) Molecular cloning: a laboratory manual. Cold Spring Harbor Laboratory Press, Cold Spring Harbor, NY

Schliewen UK, Rassmann K, Markmann M, Markert J, Kocher TD, Tautz D (2001) Genetic and ecological divergence of a monophyletic cichlid species pair under fully sympatric conditions in Lake Ejagham, Cameroon. Mol Ecol 10:1471-1488

Seutin G, White BN, Boag PT (1991) Preservation of avian blood and tissue samples for DNA analyses. Can J Zool 69:82-92

Skubic E, Taborsky M, McNamara JM, Houston AI (2004) When to parasitize? A dynamic optimization model of reproductive strategies in a cooperative breeder. J Theor Biol 227:487-501

Stiver KA, Dierkes P, Taborsky M, Balshine S (2004) Dispersal pattern and status change in a co-operatively breeding cichlid fish. Neolamprologus pulcher: evidence form microsatellite analyses and behavioural observations. J Fish Biol 65:91-105

Stiver KA, Dierkes P, Taborsky M, Gibbs HL, Balshine S (2005) Relatedness and helping in fish: examining the theoretical predictions. Proc R Soc B 272:1593-1599

Taborsky M (1984) Broodcare helpers in the cichlid fish Lamprologus brichardi-their costs and benefits. Anim Behav 32:1236-1252

Taborsky M (1985) Breeder-helper conflict in a cichlid fish with broodcare helpers - an experimental analysis. Behaviour 95:45-75

Taborsky M (1994) Sneakers, satellites, and helpers: parasitic and cooperative behavior in fish reproduction. Adv Stud Behav 23: $1-100$

Taborsky M (1997) Bourgeois and parasitic tactics: do we need collective, functional terms for alternative reproductive behaviours? Behav Ecol Sociobiol 41:361-362

Taborsky M (1998) Sperm competition in fish: bourgeois males and parasitic spawning. Trends in Ecology and Evolution 13:222-227

Taborsky M (1999) Conflict or cooperation: what determines optimal solutions to competition in fish reproduction? In: Oliveira RF, Almada V, Goncalves E (eds) Behaviour and conservation of littoral fishes. ISPA, Lisboa, pp 301-349

Taborsky M (2001) The evolution of bourgeois, parasitic and cooperative reproductive behaviors in fishes. J Heredity $92: 100-110$

Taborsky M (2008) Alternative reproductive tactics in fish. In: Oliveira RF, Taborsky M, Brockmann HJ (eds) Alternative reproductive tactics: an integrative approach. Cambridge University Press, Cambridge, pp 251-299

Taborsky M, Limberger D (1981) Helpers in Fish. Behav Ecol Sociobiol 8:143-145

Taborsky M, Grantner A (1998) Behavioural time-energy budgets of cooperatively breeding Neolamprologus pulcher (Pisces: Cichlidae). Anim Behav 56:1375-1382

Vehrencamp SL (1983a) A model for the evolution of despotic versus egalitarian societies. Anim Behav 31:667-682

Vehrencamp SL (1983b) Optimal degree of skew in cooperative societies. Am Zool 23:327-335

West SA, Pen I, Griffin AS (2002) Cooperation and competition between relatives. Science 296:72-75

Woolfenden GE, Fitzpatrick JW (1978) The inheritance of territory in group-breeding birds. Biosci 28:104-108

Wrege PH, Emlen TE (1987) Biochemical determination of parental uncertainty in white-fronted bee-eaters. Behav Ecol Sociobiol 20: $153-160$

Young AJ, Carlson AA, Monfort SL, Russell AF, Bennett NC, Clutton-Brock T (2006) Stress and the suppression of subordinate reproduction in cooperatively breeding meerkats. Proc Natl Acad Sci U S A 103:12005-12010 